\title{
Research on Contextual Memorizing of Meaning in Foreign Language Vocabulary
}

\author{
Linjing $\mathrm{Xu}^{1, *}$, Qingxia Xiong ${ }^{1} \&$ Yufang Qin ${ }^{2}$ \\ ${ }^{1}$ Postgraduate of Foreign Languages College, Jiangxi Normal University, China \\ ${ }^{2}$ Postgraduate of School of Foreign Language, Wenzhou University, China \\ *Correspondence: Postgraduate of Foreign Languages College, Jiangxi Normal University, China. E-mail: \\ xulinjing1993@qq.com
}

Received: March 15, 2018

Accepted: April 10, $2018 \quad$ Online Published: April 24, 2018

doi:10.5430/wje.v8n2p168

URL: https://doi.org/10.5430/wje.v8n2p168

This paper is a periodical achievement of the Innovation Fund Project for Graduate Students of Jiangxi Normal University on "Study on the Burnout Levels of English Majors of Normal University and Countermeasure Illustrated by the Case of Jiangxi Normal University". I appreciate the anonymous referees for the helpful comments and suggestions.

\begin{abstract}
The purpose of this study was to examine the role of contexts in the memory of meaning in foreign vocabularies. The study was based on the cognitive processing hierarchy theory of Craik and Lockhart (1972), the memory trace theory of McClelland and Rumelhart (1986) and the memory trace theory of cognitive psychology. The subjects were non-English majors freshmen. The contexts used in the study were list, sentence and text. Through timely test and delay test, it was found that sentence performed better than text, which was different from expectation. After analysis and interview, some problems were found in this study.
\end{abstract}

Keywords: contexts, meaning of vocabulary, memory

Vocabulary is the smallest language unit that makes sense, and it is the foundation of language expression. Vocabulary learning is an important part of foreign language learning. Vocabulary is a key factor influencing English learners' language skills. However, In current college English teaching, Students learn new words like monkeys go down the mountain, they learn new words and forget old words. In fact, students spend a lot of time and energy, but they do not achieve the expected results during class hours. The vocabulary has always been at the original level, which has led to the poor proficiency of English. Because they do not understand how to effectively learn words. As time passes, they lost interest in English learning. Therefore, the ability to master vocabulary is the key to learning English.

\section{Research on the Effect of Context on Vocabulary Learning and Memory at Home and Abroad}

Vocabulary learning can be divided into direct learning and indirect learning. Direct learning refers to learners doing something that can make them focus on vocabulary activities and exercises. It includes word formation exercises, reciting vocabulary, and vocabulary games. Indirect vocabulary learning means that the learners focus on other aspects, especially on language information, such as reading, listening comprehension, listening to songs, watching English movies, etc. Learners can learn vocabulary without special learning. This study focuses on the direct learning of vocabulary.

The results of foreign studies on second language vocabulary learning show that indirect learning of vocabulary is the main way to expand vocabulary in second language (Schmitt, 2002). The possibility of indirectly learning a vocabulary is extremely small, and it is only possible to learn the word if he encounters the same new word at least 7-10 times in a short period of time (Nagy, 1995). Krashen (1989), and Crothers (1967) found one word that appeared consecutively by seven times can be really grasp. Over the years, the research results have been widely 
used in English vocabulary teaching. Rundus (1970), a professor of psychology and computer science at Stanford University, used computer and other advanced equipment to conduct in-depth empirical research on the effectiveness of long and short-term memory and retelling. It was found that retelling, especially reading aloud, was beneficial to college students' word memory. Nation (1990) emphasizes that teaching students to master learning strategies is more important than imparting new words. Therefore, the English vocabulary memory strategy given to people should be the most important thing in college English vocabulary teaching.

Fan and Wang (2002) conducted independent sample testing on vocabulary learning strategies and average weekly vocabulary time for first-year English majors and third-year English majors. The results show that college English majors have multiple memory strategies in terms of memory vocabulary, and there are great differences in memory strategies between high and low grade students. Some scholars started at the graduate level and conducted empirical research on students' English vocabulary memory. Zhang(2001) selected 102 non-English major students from China Pharmaceutical University as the research subjects through a combination of questionnaire survey and vocabulary test exercises. The study found that non-English major graduate students and English major graduate students have significant differences in strategies for memorizing English vocabulary.

Foreign studies on vocabulary learning without context and contextualization are few. Mckeown and Curtis (2009) found no significant differences in the memory effect of learning vocabulary through vocabulary and discourse contexts. Context learning methods have advantages. China's research on contextual memory patterns is also rare. He (1998) found that the short-term memory of the vocabulary method is larger than the memory of the contextual method, and the memory retention rate of the contextual method is better than the vocabulary method. Ke and Dong (2001) found that the contexts that are easy to understand in the study, both in the short-term and long-term effects, are more conducive to the memory of foreign language vocabulary than word lists. Zhang and Chen (2003) found that understandable context is more effective than incomprehensible context. Many domestic research studies have shown that Chinese college students firmly believe that vocabulary should be recited (Wang, 1998; Wu and Wang, 1998), but how to effectively "recite" words is a confusing and intractable problem for learners during college English learning.

\section{The Theoretical Basis of This Study}

The term mental lexicon is derived from psycholinguistics and refers to the long-term memory of lexical knowledge in the brain. Treisman (1960) first proposed the hypothesis of the mental lexicon, and considered that the vocabulary memory of the human brain is like a dictionary. It contains many vocabulary entries. Each entry includes pronunciation, writing, semantics, grammatical functions, and applications. Recognizing a word entered by sensory information is the process by which the word's features activate the corresponding term in the mental lexicon. Since then, in order to let people have a clear and intuitive understanding of the psychological lexicon, many psycholinguists at home and abroad have put forward a variety of different metaphors. Fundamentally speaking, the psychological lexicon is a huge repository of all relevant words, meanings and usages in the brain. It is a complete knowledge system that dynamically changes in pronunciation, meaning, and number of words.

The memory process has an important influence on the storage and extraction of mental words. The human memory process includes sensory memory, short-term memory and long-term memory. To make these vocabularies become mental words, these vocabularies must be further processed so that they can be stored for a long time or even permanently, and the words that form long-term memories will turn into mental words. The theory of information processing level proposed by Craik (1975) and memory connection theory of McClelland and Rumelhart (1986) provide the theoretical basis for this research. According to the information processing level theory, the maintaining of information is depending on the level of information processing. The theory holds that information processing must go through a number of different levels of analysis, starting from superficial sensory analysis to deeper and more complex abstract semantic analysis. Superficial sensory analysis involves the visual or auditory features of stimuli, while deeper, semantically processed stimuli, extractions of meanings, are associated with existing cognitive structures. Craik also distinguished between two different types of retelling - maintenance rehearsal and elaborative rehearsal. Maintenance rehearsal has a simple and repetitive processing activity. It cannot combine the information being processed with the information in long-term memory. elaborative rehearsal is a deep processing activity that attempts to match the information being processed with the information in long-term memory. Combined. Craik believes that only fine retelling can improve the retention of information in long-term memory. Memory traces are by-products of information processing. The persistence of traces is a direct function of the depth of processing. The deeper the processing, the longer the memory traces. The information that was deeply analyzed, involved in refined 
associations and representations produced strong memory traces that lasted longer, while those that were only superficially analyzed only produced weaker memory traces that lasted for a short period of time.

The memory connection theory of McClelland and Rumelhart is the result of the joint development of cognitive psychology, neuropsychology, and computer science. It describes cognition as a network of connections consisting of simple and large number of processing units. Connectionism does not regard cognition as a symbolic operation, but as an overall activity similar to a network system composed of neurons. The network is composed of nodes. Each node has different activities, which can make other nodes excited or suppressed, and can also be affected by the excitement or inhibition of other nodes. Different activation patterns composed of processing units can explain different cognitive processes. The knowledge as a memory storage material is stored in the connection between the units. Learning is to establish a new connection or change the activation intensity between links. In this model, the acquisition or storage of learning or certain knowledge is achieved through the change and adjustment of the node connection relationship between all units in a certain network. Certain knowledge is stored in this type of specific network relationship. Similarly, the use and extraction of relevant knowledge is also achieved through the processing of nodes distributed in the network.

\section{Research Methods}

\subsection{Research Objects}

The research objects were some non-English major freshmen from a certain university in Jiangxi Province. They were assigned to the same class after a unified English proficiency test. This shows that the subjects' learning ability and English proficiency are quite the same.

\subsection{Research Design}

The memory material was selected from "Like a Duck to Water - level 4", in which the author obtained 30 target vocabularies through lexical difficulty screening, and all target vocabularies were real words; then the author divided the 30 content words into three groups equally: First The group was in the format of the word list, with phonetic symbols, part of speech and Chinese meanings; the second group was in the example sentence format, marked with phonetic symbols, part of speech, Chinese meaning, English and Chinese bilingual sentences; the third group was the discourse format, and 10 target words exist in the In a short essay, each vocabulary was marked with phonetic symbols, part of speech, and Chinese. The independent variable were the vocabularies learning methods, i.e. the word list, sentence, and context. The dependent variable was the vocabulary memory effect of the subject and was embodied as the test result. Recalling the Chinese meaning of each English word on the test volume corresponded to 1 Points, a total of 30 points.

\subsection{Prediction of Research Results}

The author's research results based on the memory processing theory and the memory connection theory predict that the text has the best memory effect on lexical meaning, followed by example sentences, and the word list has the worst effect.

\subsection{Research Process}

Each subject learned the memory of the target words and its Chinese meaning within the same time (30 minutes), under the three learning conditions designed by the experiment. Inform all the participants that they will have meaning test, but do not tell them that there is a time-delay test to prevent the subject from deliberately reviewing the memory outside the class. After the learning, were collected the learning materials and handed out the test papers immediately. One week later, a delay test was performed. The order of vocabulary was adjusted during the delay test to prevent any possible impact of the previous test on this test.

\section{Results and Discussion}

\subsection{Research Results}

The results in Table 1 show that the vocabulary memory averages in the vocabulary, sentence context, and discourse context in timely testing were 9.26, 9.45, and 9.07, respectively. The results in Table 2 show that the memory averages of the vocabulary, sentence context, and textual context in the delayed test one week later were 7.52, 8.63, and 7.26. It can be seen that the three contextual memory scores of the delayed test are lower than the instant test. In 
all contexts, the effect of sentence context memory was the best, and the average points in the timely test and the delay test were higher than the other two contextual memory effects.

Table 1. Descriptive Statistics of Vocabulary Memory Effect in Timely Tests

\begin{tabular}{lllllll}
\hline & $\mathrm{N}$ & Max & Min & Mean & $\begin{array}{l}\text { Standard } \\
\text { Deviation }\end{array}$ & variance \\
List01 & 42 & 10 & 6 & 9.26 & 1.106 & 1.222 \\
Sentence01 & 42 & 10 & 4 & 9.45 & 1.273 & 1.620 \\
Text01 & 42 & 10 & 4 & 9.07 & 1.702 & 2.897 \\
\hline
\end{tabular}

Table 2. Descriptive Statistics of Vocabulary Memory Effect after One Week

\begin{tabular}{lllllll}
\hline & $\mathrm{N}$ & Max & Min & Mean & $\begin{array}{l}\text { Standard } \\
\text { Deviation }\end{array}$ & variance \\
List02 & 42 & 10 & 2 & 7.52 & 2.511 & 6.304 \\
Sentence02 & 42 & 10 & 0 & 8.36 & 2.162 & 4.674 \\
Text02 & 42 & 10 & 0 & 7.26 & 3.100 & 9.613 \\
\hline
\end{tabular}

As can be seen from Table 3, the Sig of the vocabulary context is $0.000<0.05$, the Sig of the sentence context is $0.004<0.05$, and the Sig of the textual context is $0.003<0.05$. This shows that there is a significant difference in the lexical memory effect of the contextual variables in the one-week delay test. In the three contexts of significant differences, the Sig of the sentence context is the largest. So the sentence context has the best effect on the lexical meaning memory, the text context is the next, and the list is the worst.

Table 3. Paired-sample T-test for Three Contextual Memory Effects in Two Tests

\begin{tabular}{|c|c|c|c|c|c|c|c|c|}
\hline & \multicolumn{8}{|c|}{ Paired Differences } \\
\hline & \multirow[t]{2}{*}{ Mean } & \multirow{2}{*}{$\begin{array}{l}\text { Standard } \\
\text { deviation }\end{array}$} & \multirow{2}{*}{$\begin{array}{l}\text { Std. } \\
\text { Error } \\
\text { Mean }\end{array}$} & \multicolumn{2}{|c|}{ Std. Error Mean } & \multirow[t]{2}{*}{$\mathrm{T}$} & \multirow[t]{2}{*}{$\mathrm{df}$} & \multirow{2}{*}{$\begin{array}{l}\text { Sig } \\
\text { (2-tailed) }\end{array}$} \\
\hline & & & & Lower & Upper & & & \\
\hline Pair 1 list01-list02 & 1.738 & 2.678 & .413 & .903 & 2.572 & 4.206 & 41 & .000 \\
\hline Pair 2 sen $01-\operatorname{sen} 02$ & 1.095 & 2.325 & .359 & .371 & 1.820 & 3.053 & 41 & .004 \\
\hline Pair 3 text01-text02 & 1.810 & 3.691 & .569 & .659 & 2.960 & 3.177 & 41 & .003 \\
\hline
\end{tabular}

\subsection{Discussion}

The main findings of this study are that sentence contexts have the most significant effect on the long-term memory of word meanings. According to the distinction between maintenance rehearsal and elaborative rehearsal, maintenance rehearsal does not bring about a good memory effect. Information cannot enter into long-term memory through mechanical retelling. Only elaborative rehearsal can improve information retention in long-term memory. According to this theory, when memorizing words, paying attention to word forms or pronunciations is a shallow-coded cognitive method, so that memorized words are easily forgotten. Attention to word meanings results in deeper and richer representations, and memory traces are more persistent. This is a deep-coded cognitive approach. The deeper the processing level of the word, the better the memory effect of the word. In the process of constructing new and old words meaningfully from word to sentence and then from sentence to discourse, learners must invest in a deeper level of cognitive processing to achieve the entire meaning construction. The memory connection theory of McClelland and Rumelhart (1986) indicates that information is not stored separately in the memory system, but is linked together through discourse meanings to constitute a meaningful semantic network, which can provide effective clues for vocabulary extraction.

The rephrasing of the vocabulary can be viewed as a simple mechanical retelling of surface features of the word such as phonetics, orthography, meaning, etc. Sentence context can provide a deep semantic processing environment for 
word learning. In theory, context should be more conducive to semantic processing than sentence context. However, in this experiment, the discourse context was slightly weaker than that of the sentence context. The experimental results were slightly inconsistent with the memory processing theory and the memory connection theory. After analysis and interviews, the author summarized several problems in this experiment.

First, there are deficiencies in experimental design. There was no pre-test before this study, and it was difficult to grasp the time required for the study. The memory duration will also affect the research results to some extent. There may be problems with the selected memory words. Words are not evenly distributed, and simple or difficult words are tied together, resulting in the fact that it is too easy or too difficult to do the work.

Second, time affects. In a certain period of time, the vocabulary group has more time for target words and discourse context learning requires learning an article to memorize vocabulary. They may not have enough time to focus on the target word. Therefore, in the test, the memory effect of the vocabulary group was better than that of the discourse group.

Third, motivation affects. Because before the experiment, the subject was informed of the experiment's purpose and told that there would be a test after the memory. So the purpose is "impure", causing the subject to concentrate too much on the Chinese meaning of the word, ignoring the other aspects of the word. In the discourse context, the subjects focused on the target words in the text with the purpose of reciting words, and found the words to start recite blindly. In the interview, the author learned that some students did not read the full article; some students only read the Chinese translation of the article; some students did not even read the article and found the target directly. Due to the influence of this situation, the discourse context did work well.

\section{Conclusion}

This study selects an important aspect of the vocabulary learning process - the lexical meaning memory test. The conclusion is that the sentence context has the best memory effect and memory. In addition to the problems mentioned above, there are still many aspects that need further consideration: such as the choice of vocabulary size, the length of memory, the size of the test population, and the frequency of testing. Therefore, the results of this study are only responsible for this this experiment. Although the results are slightly different from expectations, this does not deny the information processing level theory and the memory connection theory. In the process of college English teaching, teachers should guide students to choose different vocabulary learning methods according to their learning goals. In preparation for word dictation tasks, vocabulary forms can be used for review. In the short-term expansion of vocabulary, sentence contexts can be used. Theoretically, discourse context is most conducive to vocabulary long-term memory, so teachers should encourage students to use it to remember words. The most important point is that students should change their motives for recitation of words, not to recite words in order to recite words, and find a suitable method for them. Only in this way can they really achieve the goal of improving English.

\section{Acknowledgments}

I am very grateful to my supervisor professor Tang, Xiongying, my fiancé Chen, my friends Qin, Yufang and Cheng, Ailian for their helpful comments and suggestions. Thanks all the participants and volunteers in the study.

\section{References}

Cheng, D. F. (2010). The role of context in the direct learning of foreign language vocabulary. Journal of Fujian Normal University (Philosophy and Social Science), 6, 113-118.

Craik, F. I. M. (1975). Depth of processing and the retention of words in episodic memory. Journal of Experimental Psychology General, 104(3), 268-294. https://doi.org/10.1037/0096-3445.104.3.268

Crothers, E., \& Suppes, P. (1967). Some remarks on stimulus-response theories of language learning. Experiments in Second-Language Learning, 1-25. https://doi.org/10.1016/B978-0-12-395568-5.50005-3

Dai, C. H. (2006). The influence of linguistic ability on two language acquisition. Foreign Language Teaching and Research, 38(6), 451-459.

Fan, L., \& Wang, Q.H. (2002). An Experimental Study of Classified Organization Strategies in English Vocabulary Learning. Foreign Language Teaching and Research, 34(3), 209-212. 
Fergus I.M. Craik \& Robert S. Lockhart. (1972). Levels of processing: a framework for memory research. Journal of Verbal Learning \& Verbal Behavior, 11(6), 671-684. https://doi.org/10.1016/S0022-5371(72)80001-X

He, J. N. (1998). An experimental study of the effects of lexical presentation on vocabulary memory. Foreign Language Teaching in Shandong, 2, 60-63.

Ke, W., \& Dong, Y. P. (2001). A study of the effect of context in the direct study of second language vocabulary. Modern Foreign Language, 24(4), 352-358.

Krashen, S. (1989). We acquire vocabulary and spelling by reading: additional evidence for the input hypothesis. Modern Language Journal, 73(4), 440-464. https://doi.org/10.1111/j.1540-4781.1989.tb05325.x

Mcclelland, J. L. (1986). Parallel distributed processing: explorations in the microstructure of cognition. vol. 1: foundations. Language, 63(4), 45-76.

Mckeown, M. G., \& Curtis, M. E. (2009). The Nature of Vocabulary Acquisition. Psychology Press.

Nagy, W. E. (1995). On the role of context in first- and second-language vocabulary learning. Context Clues, 24.

Nation, Paul. (1990). Teaching and Learning Vocabulary. New York: Newbury House Publishers.

Rumelhart, D. E., Mcclelland, J. L., \& Group, C. P. (1986). Parallel distributed processing: explorations in the microstructure of cognition. vol. 2: psychological and biological models. Language, 63(4), 45-76.

Rundus, D., \& Atkinson, R. C. (1970). Rehearsal processes in free recall: a procedure for direct observation. Journal of Verbal Learning \& Verbal Behavior, 9(1), 99-105. https://doi.org/10.1016/S0022-5371(70)80015-9

Schmitt, D. (2002). Learning vocabulary in another language. i.s.p. nation. ELT Journal An International Journal for Teachers of English to Speakers of Other Languages, 56(1), 91-93. https://doi.org/10.1093/elt/56.1.91

Treisman, A. M. (1960). Contextual cues in selective listening. Quarterly Journal of Experimental Psychology, 12(4), 242-248. https://doi.org/10.1080/17470216008416732

Victori, R. M. (1991). The nature of vocabulary acquisition. Tesol Quarterly, 25(4), 717-719. https://doi.org/10.2307/3587087

Wang, W.Y. (1998). Ideas, strategies and English vocabulary memory. Foreign Language Teaching and Research: Foreign Language Bimonthly, 1, 49-54.

Wu, X., \& Wang, Q. (1998). Vocabulary learning strategies for non English Majors. Foreign Language Teaching and Research: Foreign Language Bimonthly, 1, 55-59.

Zhang, R.H., \& Cheng, J.X. (2003). The effect of the nature of context on vocabulary memory. Research on Foreign Language Teaching in Basic Education, 4, 25-27.

Zhang, P. (2001). Postgraduates' basic English and professional English vocabulary learning strategies. Foreign Language Teaching and Research: Foreign Language Bimonthly, 33(6), 442-449. 